Ave, Mailstop S-32, Cleveland, OH 44195.

98-OA-119. Qureshi M, Gordon SM, Yen-Lieberman B, Litaker $D G$. Controlling varicella in the healthcare setting: barriers to varicella vaccination among healthcare workers. Infect Control Hosp Epidemiol 1999;20:516-518.

\section{REFERENCES}

1. Orenstein $\mathrm{W}$, Bernier $\mathrm{RH}$. Crossing the divide from vaccine technology to vaccine delivery. The critical role of providers. JAMA 1994;272:1138-1139.

2. Becker MH, Maiman LA. Sociobehavioral determinants of compliance with health and medical care recommendations. Med Care 1975;13 $10-24$.
3. Murata PJ, Young LC. Physicians' attitudes and behaviors regarding hepatitis B immunization. I Fam Pract 1993;36:163-168.

4. Ballada D, Biasio LR, Cascio G, D'Alessandro D, Donatelli I, Fara GM, et al. Attitudes and behavior of health care personnel regarding influenza vaccination. Eur J Epidemiol 1994;10:63-68.

5. Rushton TC, Ganguly R, Sinott JT IV, Banerji M. Barriers to immunization-an examination of factors that influence the application of pneumococcal vaccine by house staff. Vaccine 1994;12:1173-1179.

6. Salzman MB, Sharrar RG, Steinberg S, LaRussa P. Transmission of varicella-vaccine virus from a healthy 12 -month old child to his pregnant mother. J Pediatr 1997;131;151-154.

7. Lyznicki JM, Bezman RJ, Genel M. Report of the Council of Scientific Affairs American Medical Association: immunization of healthcare workers with varicella vaccine. Infect Control Hosp Epidemiol 1998;19:348-353.

\title{
Salmonella Sources in the Home
}

Gina Pugliese, RN, MS Martin S. Favero, PhD

To explore the role of foods and the home environment in the development of Salmonella infections in infants and children, researchers from the Arkansas Childrens Hospital, Little Rock, conducted home investigations of patients younger than 4 years of age infected with Salmonella.

A total of 526 cultures from 50 homes were obtained from foods (120); household members (73); refrigerators (52); water (47); countertops (46); soil (42); can openers (36); vacuum cleaners (34); animals, pets, insects (26); and others (50). Isolates with a serotype identical to those in the index patient were found in 16 homes, 3 of which included an isolate of a second serotype, and an isolate of a different serotype was recovered in 3 homes. The pulsed-field gel electrophoresis patterns of the isolates of identical serotypes from the subjects and from their environment were indistinguishable in all but two patients. Among isolates of the same serotype encountered in different homes, all patterns were different. The identical serotype was found in multiple locations (4); dirt surrounding front doors (4); household members
(3); vacuum cleaner (1); animals, pets, insects (1); and a refrigerator shelf (1).

The authors noted that these data illustrate the importance of the child's environment in the development of salmonellosis and suggest that clinicians concentrate on educating the parents about the environmental spread of Salmonella. Contaminated foods in the home play a less significant role in the infection of infants and children.

FROM: Schutze GE, Sikes JD, Stefanova R, Cave MD. The home environment and salmonellosis in children. Pediatrics 1999;103:E1. 